\title{
Metal-Binding Ability of Leu-Enkephalin, Related Glycoconjugates and Peptidomimetics
}

\author{
Zsuzsa Majer, ${ }^{1}$ Elemér Vass, ${ }^{1}$ Maja Roščić, ${ }^{2}$ Miklós Hollósi, ${ }^{1}$ Štefica Horvat, ${ }^{2}$ Andreja Jakas ${ }^{2, *}$
}

1 Eötvös Loránd University, Institute of Chemistry, Laboratory for Chiroptical Structure Analysis, Pázmány Péter sétány 1/A, H-1117, Budapest, Hungary
2 Ruđer Bošković Institute, Division of Organic Chemistry and Biochemistry, Bijenička c. 54, HR-10000 Zagreb, Croatia
${ }^{*}$ Corresponding author's e-mail address: andreja.jakas@irb.hr

RECEIVED: August 26, 2015 * REVISED: October 20, 2015 * ACCEPTED: October 26, 2015

Abstract: Both the chemistry and consequences of the nonenzymatic reaction between reducing sugars and reactive amino groups of amino acids, peptides and proteins (known as the Maillard reaction), have received considerable attention in food and health science fields. This initial reaction results in Amadori and similar products formation, followed by degradation to advanced glycation end products (AGEs). It is well established that AGEs are associated with color and odor of thermally processed or stored food, as well as with pathogen products in a number of diseases. The model systems of early stage Maillard reaction products (MRP) were prepared between endogenous opioid peptide leucine enkephalin (1) and D-glucose / D-glucuronic acid. The complexation ability of prepared MRP with metal ions $\left(\mathrm{Ca}^{2+}, \mathrm{Zn}^{2+}, \mathrm{Al}^{3+}, \mathrm{Pb}^{2+}\right.$ and $\left.\mathrm{Cu}^{2+}\right)$ was investigated and compared to the complexation ability of parent peptide using ECD and FTIR spectroscopic measurements.

Keywords: Amadori compound, hydroxypyridinium, imidazolidinone, Maillard reaction, metal complex.

\section{INTRODUCTION}

T RANSITION metal ions are found in living organisms, coordinated to different biomolecules and participating in many biochemical reactions where they play a crucial role. Carbohydrates, although involved in many biochemical processes, immunological events, and pathological conditions, exhibit relatively poor coordinating properties and form weak complexes with metal ions, however, an increased metal-binding ability has been linked to the glycated proteins formed in Maillard reaction. ${ }^{[1-4]}$ In such reversible reaction, reducing sugars react with amino acids, peptides or proteins, producing Amadori, Heyns, and other similar compounds, which can further form irreversible AGE (Advanced Glycation End) products. There is accumulating evidence for the ability of Maillard reaction products (MRP) to complex metal ions. [5] It is well known that metal ions can form complexes of various properties with MRPs, oxidize Amadori compounds as well as their derivatives, and catalyze further interactions of these compounds. ${ }^{[5-7]}$ In addition, transition elements accelerate the formation of Amadori compounds, as well as their polymerization products during the final stage of the Maillard reaction. ${ }^{[6-14]}$
Nevertheless, the information about MRP complexes and whether complexations of individual MRPs are likely to influence internal metabolism in vivo is not currently available.

We know that the type of cation is important for the chelating ability of MRPs, as well as its role in the stability of the complexes formed, and the accumulation of chromophores in reaction systems. ${ }^{[5,15,16]}$ Moreover, the browning reaction rate studied in heated solutions of Amadori compounds depends not only on the amounts of metal salts added, but also on the valence of the cations, ${ }^{[6,17]}$ and $\mathrm{pH}$ of the solution. ${ }^{[18]}$

Since formations of metal complexes are associated with different but unknown MRP ligands, we have explored the ability of several MRPs with known structures to complex with several biologically relevant metal ions. ${ }^{[19]}$ For instance, the importance of copper in human metabolism is its involvement in oxidative processes. ${ }^{[20-25]}$ Aluminum was chosen due to its high presence in the environment and extensive use in modern daily life (diets and medication). However, there is no known physiological role for aluminum within the body and hence this metal may strongly alter normal cellular metabolic pathways and produce adverse physiological effects. ${ }^{[26]}$ Calcium is important for 
healthy bones, but the question is if it is responsible for kidney stones formation, and calcification of blood vessels. The strong and selective binding of calcium(II) ions to proteins is related to the regulation of many physiological functions. ${ }^{[27]}$ Zinc is known to be essential for all highly proliferating cells in the human body, especially the immune system, but high dosage of zinc evokes the same negative effects as those observed with zinc deficiency. ${ }^{[28]}$ The toxicological effects of lead include neurotoxicity, carcinogenicity, reproductive toxicity, and neurobehavioral/developmental effects. ${ }^{[29]}$ Thus, investigation concerning difference in complexation ability for these metal ions of natural peptides and their MRPs is of essential importance. The ability of complexation of $\mathrm{Zn}^{2+}, \mathrm{Al}^{3+}, \mathrm{Ca}^{2+}$, $\mathrm{Pb}^{2+}$ and $\mathrm{Cu}^{2+}$ multivalent cations with endogenous opioid peptide Leu-enkephalin (1) $)^{[30,31]}$ and four different Leuenkephalin MRPs 2-5 was investigated. Electronic circular dichroism (ECD) and Fourier transform infrared (FTIR) spectroscopy, as complex spectroscopic methods, were used to characterize the conformation and the cationinduced conformational changes of peptides 1-5.

\section{EXPERIMENTAL}

Leu-enkephalin (1) was purchased from Bachem. Amadori compounds, $\quad N$-(1-deoxy-D-fructos-1-yl)-L-tyrosylglycylglycyl-L-phenylalanyl-L-leucine (2) and $N$-(1-deoxy-D-fructofuranos-1-yl-uronic acid)-L-tyrosyl-glycylglycyl-L-phenylalanyl-L-leucine (4) were synthesized under the conditions described by Horvat et al. (1998) ${ }^{[32]}$ and Horvat et al. (2007). ${ }^{[33]}$ Imidazolidinone derivative, $N$-\{[2-(D-gluco-pentitol-1-yl)-4- (4 - hydroxybenzyl) - 5 - oxoimidazolidin-1-yl]acetyl\}glycyl-L-phenylalanyl-L-leucine (3) was obtained as described by Roščić and Horvat (2006). ${ }^{[34]} N$-[2-(4-hydroxybenzyl)-2-(3-hydroxypyridin-1-ium)ethanoyl]glycylglycyl-L-phenylalanyl-L-leucine (5) was obtained as described by Horvat et al. (2007). ${ }^{[33]}$ All compounds were desalted using an octadecylsilica solid-phase extraction (SPE) cartridge (500 mg, $2.8 \mathrm{~mL}$ ). The following compounds all purchased from Sigma-Aldrich were used as metal ions source: $\mathrm{Al}\left(\mathrm{ClO}_{4}\right)_{3} \times 1 \mathrm{OH}_{2} \mathrm{O}, \mathrm{Ca}\left(\mathrm{ClO}_{4}\right)_{2} \times 4 \mathrm{H}_{2} \mathrm{O}, \mathrm{Cu}\left(\mathrm{ClO}_{4}\right)_{2} \times 6 \mathrm{H}_{2} \mathrm{O}$, $\mathrm{Zn}\left(\mathrm{ClO}_{4}\right)_{2} \times 6 \mathrm{H}_{2} \mathrm{O}$ and $\mathrm{Pb}\left(\mathrm{ClO}_{4}\right)_{2} \times 3 \mathrm{H}_{2} \mathrm{O}$. ECD titrations were performed at peptide : metal ratios ranging from $1: 0.25$ to $1: 5$, by adequately mixing stock solutions of peptides $(0.4 \mathrm{mM})$ and different metal ions $(25 \mathrm{mM})$. The concentrations of peptides were between $0.2-0.4 \mathrm{mg} \mathrm{mL}^{-1}$ and concentrations of metal salts between 1-6 mg mL $\mathrm{m}^{-1}$. The solvents for the spectroscopic studies were 2,2,2-trifluoroethanol (TFE; Aldrich, NMR grade), and double distilled water.

\section{ECD Measurements}

Electronic circular dichroism (ECD) spectra were recorded on a Jasco J-810 spectropolarimeter at room temperature in a quartz cell with $0.2 \mathrm{~mm}$ path length in the $185-280 \mathrm{~nm}$ (far UV) and with $10.0 \mathrm{~mm}$ path length in the $250-320 \mathrm{~nm}$ (near-UV) region. The peptide:metal ratio is expressed with $r_{\text {cat }}=$ cation / peptide and titration was running at $r_{\text {cat }}=$ $0.25-5$. ECD band intensities are expressed in mean residue ellipcity $\left([\Theta]_{\mathrm{MR}} ; \operatorname{deg} \mathrm{cm}^{2} \mathrm{dmol}^{-1}\right)$.

\section{FTIR Measurements}

FTIR spectra of $2 \mathrm{~cm}^{-1}$ resolution were recorded on a Bruker Equinox 55 spectrometer equipped with liquid $\mathrm{N}_{2}$-cooled MCT detector. The spectra were obtained at room temperature in a $\mathrm{CaF}_{2}$ cell of $0.2 \mathrm{~mm}$ path length. The sample concentration in TFE (or a TFE solution containing 2, 8 or 12 $\mathrm{mM}$ Ca perchlorate) was $4 \mathrm{mM}$ in each measurement. The spectra were corrected with the background.

\section{RESULTS AND DISCUSSION}

\section{ECD Spectroscopic Characterization of Compounds and Their Metal Complexes}

Investigation of the endogenous opioid peptide Leuenkephalin under Maillard reaction conditions (nonenzymatic glycation) lead to the chemical transformations of Leu-enkephalin (1) (Figure 1). Two glycation products resulted from the reaction of D-glucose (Glc) and Leuenkephalin (1) as early glycation products. The first product is Amadori compound $\mathbf{2}$ in which the linear peptide is alkylated at the $\mathrm{N}$-terminal position by a 1-deoxy-D-fructose unit. The second product in the reaction is compound $\mathbf{3}$ which has characteristic rigid 5-membered imidazolidinone ring. In this adduct an imidazolidinone moiety connects the acyclic sugar residue with the linear peptide chain. Early glycation products in the reaction of D-glucuronic acid (GlcA) and Leu-enkephalin are Amadori compound $\mathbf{4}$ and aromatic 3-hydroxypyridine derivative $\mathbf{5}$.

In aim to determine the complexation potential of compounds 1-5 first of all ECD spectra of these synthetic peptides were recorded (Figure 2). According to the spectrum and previous investigation it was concluded that Leu-enkephalin $\mathbf{1}$ is present in TFE as a mixture of conformers with no dominant recognizable conformation. ${ }^{[35,36]}$ The ECD spectra of Amadori compounds $\mathbf{2}$ and $\mathbf{4}$ do not differ significantly from that of $\mathbf{1}$ which suggests no strong difference in distribution of backbone conformers from peptide 1. The ECD spectrum of the imidazolidinonederivative 3 shows a broad positive band centered at $\lambda \sim 206 \mathrm{~nm}$ suggesting the influence of imidazolidinone ring on the conformation of Leu-enkephalin. The 3-hydroxypyridinium derivative $\mathbf{5}$ shows a markedly different ECD spectrum featuring with a weak positive band centered at $\sim 220 \mathrm{~nm}$, a negative band at $202 \mathrm{~nm}$ and a positive one at $191 \mathrm{~nm}$ due to structure of 3-hydroxypyridinium ring. It is 


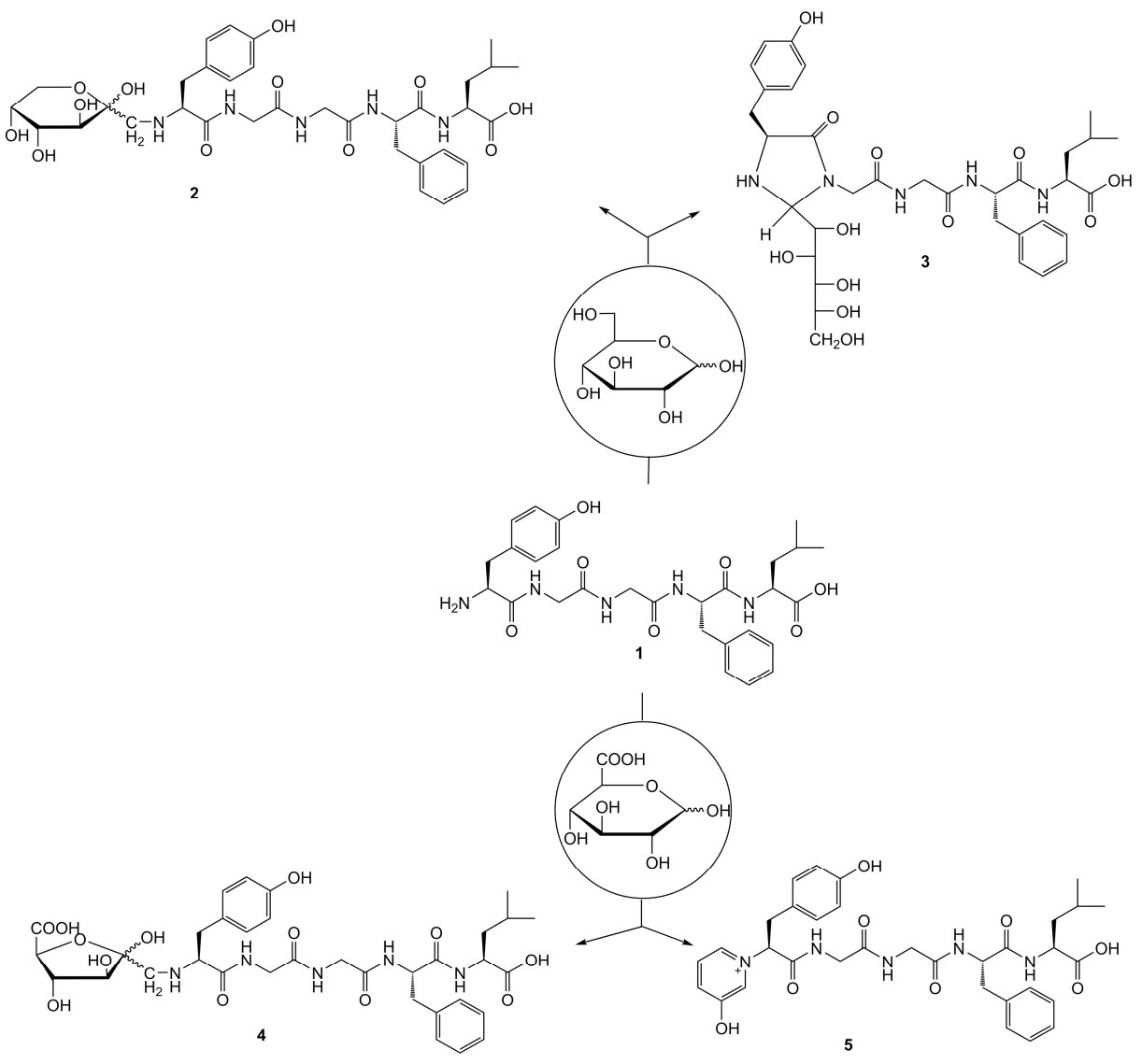

Figure 1. Formation of early glycation products of Leu-enkephalin (1) with glucose (GIc) and glucuronic acid (GIcA).

obvious that different MRPs of Leu-enkephalin have different effect on the structure of peptide 1 , which can produce difference in peptide stability and activity. ${ }^{[7]} \mathrm{ECD}$ spectra in TFE of MRP peptides 2-5 were measured in the presence of different types of cations and at their different ratio to study the conformational effect / binding type of multivalent cations $\mathrm{Zn}^{2+}, \mathrm{Al}^{3+}, \mathrm{Ca}^{2+}, \mathrm{Pb}^{2+}$, and $\mathrm{Cu}^{2+}$. There have been many attempts to categorize various metal ions and anions to predict reactivity, solubility, etc. According to Pearson (1963) ${ }^{[37]} \mathrm{Al}^{3+}$ and $\mathrm{Ca}^{2+}$ are hard Lewis acids, $\mathrm{Zn}^{2+}$ is strong Lewis acid, $\mathrm{Cu}^{2+}$ and $\mathrm{Pb}^{2+}$ soft Lewis acids are in borderline; while carboxyl, amide and hydroxyl groups belong to the hard Lewis bases. Hard acids and bases are small, compact, and non-polarizable. Hard acids tend to bind to hard bases to form adducts with ionic character while soft acids tend to bind to soft bases and theirs adducts are more covalent in nature. In oligopeptides both terminal groups, the amide and carboxyl group and the functional side chain groups (carboxyl-, amino-, thioether-, thiyl-, imidazolyl group) are potential binding sites for cations. If the amino terminal group is free, the side chain primarily serves as anchor of metal ion. Since $\mathrm{Al}^{3+}$ and $\mathrm{Ca}^{2+}$ are strong Lewis acids and hard metals, they are expected to react with the $O$-donors, such as e.g. carboxylate ion (C-terminal or side chain $\mathrm{COO}^{-}$of peptides), phenolate $\left(\operatorname{Tyr}\left(\mathrm{O}^{-}\right)\right)$and also deprotonated hydroxyl group from carbohydrates to form glycopeptide-metal complexes. $\mathrm{Zn}^{2+}$ and $\mathrm{Cu}^{2+}$ ions can bind to the terminal amino and/or carboxyl groups (mostly they are labile). More stable complex (chelatetype) is expected to form involving the terminal amino and either the neighboring amide carbonyl groups (in the case of $\mathrm{Zn}^{2+}$ ) or deprotonated amide nitrogen atom. The formation of complexes through peptide backbone will affect the character of the ECD spectra.

The aim of the present study was twofold: i) studying the ability of complexation of each compound 1-5 with various cations; ii) comparison of the complexation ability of MRPs 2-5 with the ability of complexation of peptide $\mathbf{1}$. The cation-induced ECD spectral changes in spectra of peptides 1-5 were measured from "stable complexes" at $r_{\text {cat }}$ where increasing cation concentration caused no more ECD-changes. Compounds 2-5 as Amadori, imidazolidinone and 3-hydroxypyridinium derivatives of Leu-enkephalin (1) 

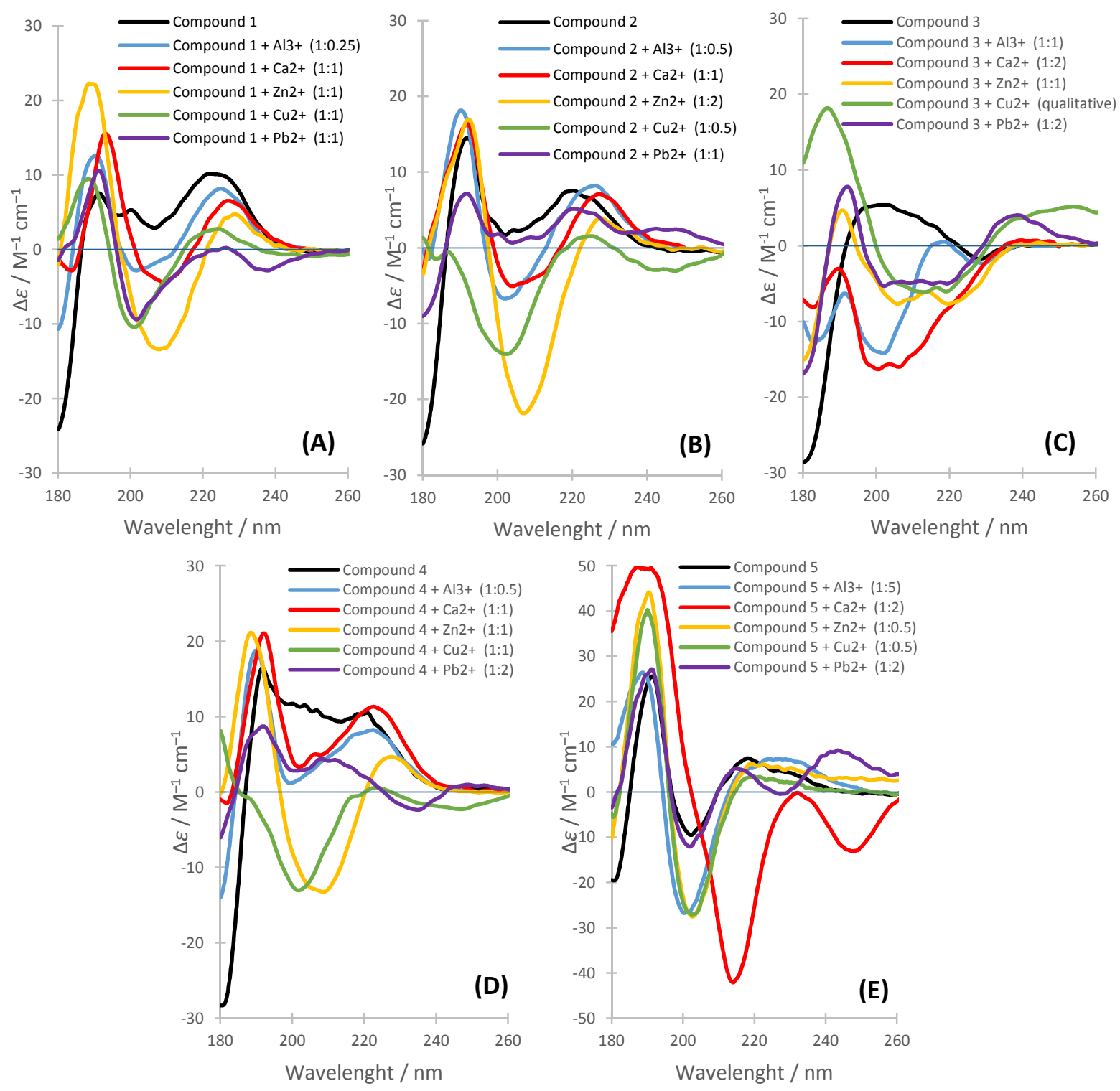

Figure 2. $C D$ spectra of (A) Compound 1; (B) Compound 2; (C) Compound 3; (D) Compound 4; (E) Compound 5; and their complexes with $\mathrm{Al}^{3+}, \mathrm{Ca}^{2+}, \mathrm{Zn}^{2+}, \mathrm{Cu}^{2+}$ and $\mathrm{Pb}^{2+}$ ions.

can give more potential cation-binding places then the corresponding parent peptide $\mathbf{1}$.

Leu-enkephalin 1 with the cations $\mathrm{Pb}^{2+}, \mathrm{Cu}^{2+}$ and $\mathrm{Al}^{3+}$ shows the adoption of more folded conformers stabilized by free carboxyl and/or side chain binding at $r_{\text {cat }} \leq 1$. These ECD spectra are characterized by a negative band near $205 \mathrm{~nm}$ and positive bands near $\sim 190 \mathrm{~nm}$ and $230 \mathrm{~nm}$, suggesting $\beta \mathrm{I} / \mathrm{III}$ turn-type (for a classification and ECD spectroscopic features of different types of turns see ref. 38), while with $\mathrm{Cu}^{2+}$ an extra negative peak with weak intensity around $240 \mathrm{~nm}$ appeared. In the presence of $\mathrm{Ca}^{2+}$ all extremes are red shifted with 5-10 nm ( $\beta$ II turn-type, Figure $2 \mathrm{a}$ ), while with $\mathrm{Zn}^{2+}$ all peaks are more intense and broader indicating a lot of different turn-types.

Amadori compound 2 (Figure $2 \mathrm{~b}$ ) gave $\beta \mathrm{I} / \mathrm{III}$ turntype, C-like spectrum with $\mathrm{Ca}^{2+}$ at $r_{\mathrm{Ca}}=1$ as a stable complex, with two negative bands above 205 and $218 \mathrm{~nm}$ and a positive band at $\sim 195 \mathrm{~nm} \cdot{ }^{[37,38]}$ With $\mathrm{Zn}^{2+}$ compound 2 shows a spectrum marked by a strong positive band at $\sim 195 \mathrm{~nm}$, a weaker one at $\sim 225 \mathrm{~nm}$ and a strong, broad negative band centered at $208 \mathrm{~nm}$. This spectral feature indicates the presence of a mixture of folded conformers, 

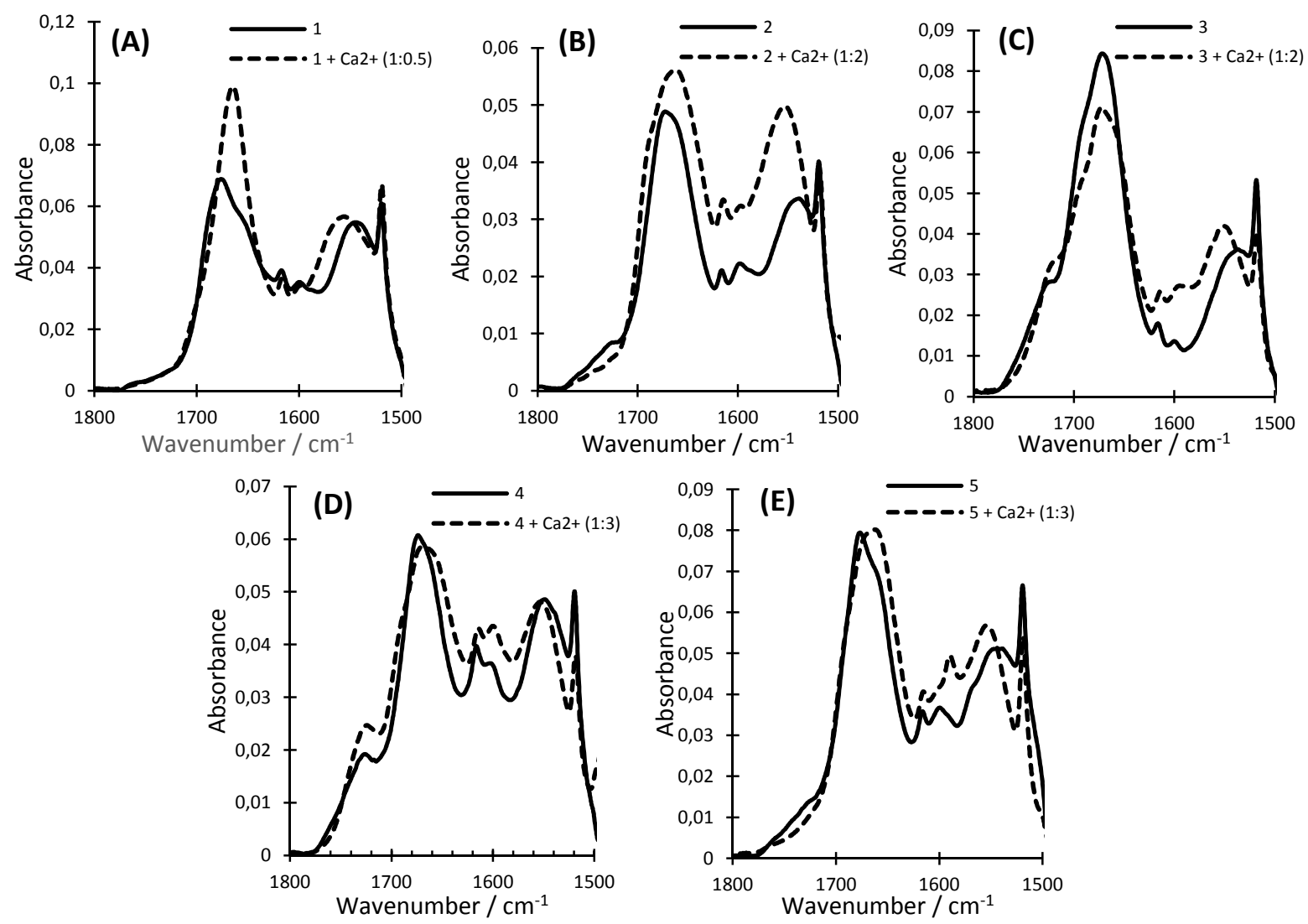

Figure 3. FTIR spectra of (A) Compound 1; (B) Compound 2; (C) Compound 3; (D) Compound 4; (E) Compound 5; and their complexes with $\mathrm{Ca}^{2+}$ ion.

mainly $\beta$ - and $\gamma$ - turn. ${ }^{[38]}$ In the presence of $\mathrm{Cu}^{2+}$ the ECD spectrum shows a strong, very broad negative band centered at $\sim 200 \mathrm{~nm}$ and a weaker one at $\sim 240 \mathrm{~nm}$.

Imidazolidinone compound $\mathbf{3}$ (Figure $2 \mathrm{c}$ ) gave more or less $\beta \mathrm{I} / \mathrm{III}$ turn-type $\mathrm{C}$-like spectra with all cations except $\mathrm{Al}^{3+}$. The cation-induced ECD spectra of compound $\mathbf{3}$ (Figure 2c) are generally marked by a very broad negative band between 200-230 nm with more overlapping extremes. $\mathrm{Al}^{3+}$ gave an unusual ECD shape which can suggest different complexation with the various functional groups.

In Amadori compound 4 (Figure 2d) free carboxylic acid can contribute to the complex formation but only subtle spectral effect with $\mathrm{Ca}^{2+}\left(r_{\mathrm{cat}}=1\right), \mathrm{Al}^{3+}\left(r_{\mathrm{cat}}=0.5\right)$ and $\mathrm{Pb}^{2+}\left(r_{\text {cat }}=2\right)$ were observed. With $\mathrm{Zn}^{2+}$ and $\mathrm{Cu}^{2+}$ ions compound 4 shows the same spectral behavior as in the case of compound $\mathbf{2}$ which can be attributed to the Amadori structure but they have also similarity with compound $\mathbf{1}$.

In the solution of 3-hydroxypyridinium derivative $\mathbf{5}$ (Figure 2e), all cations, except $\mathrm{Ca}^{2+}$, induce the same spectral character and the observed $\beta$-turn-type C-like spectra differ only in the relative band intensities which means that there is no complex formation with backbone amide carbonyl groups so there are no significant conformational changes. The only exception is $\mathrm{Ca}^{2+}$ which with 5 gave a broad and strong positive band at $190 \mathrm{~nm}$, a strong negative band at $\sim 215 \mathrm{~nm}$ and an additional weaker one at $\sim 248 \mathrm{~nm}$. This spectrum shows $\beta$-sheet like features and it is not a typical "Ca-induced spectrum", characteristic for many peptide-Ca ${ }^{2+}$ complexes, where the main features would be a weak positive band above $210 \mathrm{~nm}$ and a strong negative one at $\sim 195 \mathrm{~nm}$. ${ }^{[39]}$

\section{FTIR Spectroscopic Characterization of Compounds and Their Metal Complexes}

The infrared spectra of compounds 1-5 (Figure 3) were taken in TFE in the $1800-1500 \mathrm{~cm}^{-1}$ spectral region, which is mainly composed of bands due to $v_{\mathrm{C}=\mathrm{O}}(\mathrm{COOH})$, amide $\mathrm{I}$, amide $I /$ and $v_{\text {as }}\left(\mathrm{COO}^{-}\right)$vibrations. Absorption by the aromatic Tyr and Phe side chains also give contribution in this spectral region. The sharp component bends near 1519,1600 and $1616 \mathrm{~cm}^{-1}$ in the infrared spectra of all analyzed compounds are assigned to the ring vibrations of Tyr and Phe. Since FTIR measurements require much higher sample concentrations than ECD, which may induce 
precipitation in the presence of certain metal ions (especially $\mathrm{Al}^{3+}$ ), a systematic study with all the metal ions was not possible. Based on its high biological relevance and considering the characteristic changes observed in the ECD spectrum, the FTIR based complexation studies were restricted to the $\mathrm{Ca}^{2+}$ ion. The infrared spectra of compounds 1-5 with Ca were taken at peptide-metal ratios for which the stable complexes were observed (Figure 3 ) according to the ECD spectra. Main difference observed in complex spectra compared to compounds alone were shifts from $1542 \mathrm{~cm}^{-1}$ to $1552 \mathrm{~cm}^{-1}$ in the amide II spectral region of compounds $\mathbf{1 - 3}$ and $\mathbf{5}$, while compound $\mathbf{4}$ does not show shift of this extreme which is in agreement with ECD spectrum of compound 4 with $\mathrm{Ca}^{2+}$ where no significant changes of spectrum shape was observed. The $\mathrm{Ca}^{2+}$-induced changes observed in the FTIR spectra of compounds 1-5 are more subtle than those in ECD and do not provide sufficient information for a more detailed conformational interpretation in terms of possible types of folded structures.

\section{CONCLUSION}

In the case of short chain peptides containing aromatic amino acid residue, as Leu-enkephalin, ECD spectroscopy can give a good diagnostic of conformational changes (e.g. cations, solvent, temperature), but cannot discriminate well the aromatic contribution from the conformational effect. ${ }^{[40,41]}$ Binding of the cation to the free carboxylic group or $\mathrm{OH}$-group of side chain of Tyr can stabilize the backbone conformation of the peptide, but cation-bindings to the backbone amide carbonyl groups can have higher influence to the conformational changes. It is known that the hard metals such as $\mathrm{Ca}^{2+}$ and $\mathrm{Al}^{3+}$ ions bind to the carboxyl group, phenolic side chain of Tyr and backbone amide carbonyl group. In TFE the cation-binding involves deprotonation of the C-terminus carboxyl group or hydroxyl Tyr side chain, or sugar hydroxyl group. The zwitter-ion formation enables this reaction. Appearance of the stronger spectral feature of $\pi \rightarrow \pi^{*}$ at $195 \mathrm{~nm}$ may be attributed to folded structures stabilized by the cation.

The slight changes of the ECD shapes are similar in the case of $\mathrm{Ca}^{2+}$ and $\mathrm{Al}^{3+}$ with compounds $\mathbf{1}, \mathbf{2}$, and $\mathbf{4}$ at the same ratio. We suppose that these changes are only due to the modified distribution of the conformers. The ECD curves of compounds $\mathbf{3}$ and $\mathbf{5}$ with $\mathrm{Ca}^{2+}$ ion show characteristic conformational changes toward ordered structures. Complexation of compound $\mathbf{3}$ with $\mathrm{Al}^{3+}$ and $\mathrm{Ca}^{2+}$ results in ECD changes which might be interpreted as binding of both cations to the side chains and also to amide carbonyl(s) of the peptide backbone which results in appearance of different types of turns. Compound $\mathbf{5}$ with $\mathrm{Al}^{3+}$ shows only difference in the intensity of ECD spectra at higher $\mathrm{Al}^{3+}(1: 5)$ concentration, while with $\mathrm{Ca}^{2+}$ ion $(1: 1)$ the ECD spectrum shows a typical $\beta$-sheet-like spectrum (conformational changes involving backbone amide carbonyls) with an additional band at $248 \mathrm{~nm}$.

Compounds 1, 2 and $\mathbf{4}$ gave the same ECD shape but at different peptide / $\mathrm{Zn}^{2+}$ ratios. Primarily binding of $\mathrm{Zn}^{2+}$ to the OH-group of side chains (Tyr) and C-terminus carboxyl group is responsible for stabilizing the structure, leading to higher distribution of ordered structures. The Clike spectrum in the case of compound $\mathbf{3}$ can reflect a mixture of the different turn types, e.g. $\beta \mathrm{I} / \mathrm{III}$.

ECD spectra of compounds 2, 4 and $\mathbf{5}$ show no changes during titration with $\mathrm{Pb}^{2+}$. The ECD spectrum of compound 1 with $\mathrm{Pb}^{2+}$ shows conformational changes, mainly formation of $\beta \mathrm{I} / \mathrm{III}$ type turns and also a positive band at $\sim 240 \mathrm{~nm}$. Compound 3 with $\mathrm{Pb}^{2+}$ gave $\beta \mathrm{l} / \mathrm{III}$ turntype ECD shape, similar to that with $\mathrm{Zn}^{2+}$.

Complexation of compounds $\mathbf{1}$ and $\mathbf{5}$ with $\mathrm{Cu}^{2+}$ results in an increase of the population of ordered structures. In the case of compounds $\mathbf{2}$ and $\mathbf{4}$ the changes in the ECD spectra reflect the increase of the ordered structures and appearance of the band at $\sim 245 \mathrm{~nm}$. The measured ECD spectra of compound $3-\mathrm{Cu}^{2+}$ complexes show typical features of a mixture of $\beta \mathrm{I} / \mathrm{III}$ - and $\gamma$-turns which correlate with the changes produced by $\mathrm{Pb}^{2+}$ and $\mathrm{Zn}^{2+}$ upon complexation with compound 3.

The conformational changes of compounds 1-5 can include self-aggregation and consequently alterations in physicochemical properties and biostability of natural compounds having interesting biological activities from the medicinal chemistry viewpoint.

Acknowledgment. We gratefully acknowledge the contribution by the Ministry of Science, Education and Sports of Croatia grant No. 098-0982933-2936, the Central Hungarian Operational Program KMOP-4.2.1/B-10-20110002, the Hungarian Scientific Research Fund (OTKA) grant $N^{\circ}$ K100720 and by financial support from the bilateral Hungarian/Croatian project No. CRO-5/2006. The authors thank Prof. M. Cudic and Dr. M. C. Rodriguez for useful suggestions and comments, and Mrs M. Perc for technical assistance.

\section{REFERENCES}

[1] K. S. Kasprzak in Cytotoxic, mutagenic and carcinogenic potential of heavy metals related to human environment (Ed.: N. D. Hadjiliadis), NATO ASI Series, Dordrecht, 1997, pp. 73-92.

[2] B. Gyurcsik, L. Nagy, Coord. Chem. Rev. 2000, 203, 81.

[3] M. B. Yim, H. S. Yim, C. Lee, S.-O. Kang, P. B. Chock, Ann. N. Y. Acad. Sci. 2001, 928, 48. 
[4] S. P. Wolff, Z. Y. Jiang, J. V. Hunt, Free Radical Biol. Med. 1991, 10, 339.

[5] D. T. Ramonaityté, M. Keršiené, A. Adams, K. A. Tehrani, N. De Kimpe, Food Res. Int. 2009, 42, 331.

[6] J. A. Randleman, G. E. Inglett, Carbohydr. Res. 1990, 201, 311.

[7] A. Jakas, Š. Horvat, Bioorg. Chem. 2004, 32, 516.

[8] F. Hayase, T. Shibuya, J. Sato, M. Yamamoto, Biosci. Biotechnol. Biochem. 1996, 60, 820.

[9] I. Birlouez-Arragon, V. Moreaux, M. Nicolas, C. J. Ducanze, Food Addit. Contam. 1997, 14, 381.

[10] R. W. Hay, D. R. Williams in Amino acids, peptides and proteins, Vol. 9 (Ed.: R. C. Sheppard), The Chemical Society, London, 1978, pp. 494-520.

[11] T. Ookawara, N. Kawamura, Y. Kitagawa, N. Taniguchi, J. Biol. Chem. 1992, 267, 18505.

[12] K. N. Islam, M. Takahashi, S. Hagashiyama, T. Myint, N. Uozumi, J. Kayanoki, H. Kaneto, N. Taniguchi, J. Biochem. 1995, 118, 1054.

[13] S. Fujimoto, N. Kayakami, A. Ohara, Biol. Pharm. Bull. 1995, 18, 396.

[14] B. Sarria, M. P. Vaquero, J. Nutr. Biochem. 2001, 12, 268.

[15] J. Pokorny, Trends Food Sci. Technol. 1991, 2, 223.

[16] J. Leclere, I. Birlouez-Arragon, M. Meli, Food Chem. 2002, 76, 491.

[17] L. Bertelli, D. Torregiani, G. Bertolo, Food Chem. 1996, 55, 353.

[18] J. Pokorny, L. Pilkova, J. Davidek, H. Valentova, Nahrung 1988, 32, 767.

[19] J. O'Brien, P. A. Morrissey, Food Chem. 1997, 58, 17.

[20] R. Z. Cheng, S. Kawakishi, J. Agric. Food Chem. 1993, $41,361$.

[21] H. Horikawa, M., Okada, Y., Nikamura, A. Sato, N. Iwamoto, Free Radical Res. 2002, 36, 1059.

[22] T. Nakayama, K. Terazawa, S. Kawakishi, J. Agric. Food Chem. 1992, 40, 830.

[23] G. B. Sajithlal, P. Chithra, G. Chandrakasan, Mol. Cell. Biochem. 1999, 194, 257.
[24] R. Cheng, S. Kawakishi, J. Agric. Food Chem. 1994, 42, 700.

[25] G. Cerchiaro, G. A. Micke, M. F. M. Tavares, A. M. D. C. Ferreira, J. Mol. Catal. A: Chem. 2004, 221, 29.

[26] R. B. Martin in: Aluminium in biology and medicine (Eds.: D. J. Chadwick, J. Whelan), Wiley, Chichester, 1992, pp. 5-25.

[27] M. J. Kronman, Crit. Rev. Biochem. Mol. Biol. 1989, 24, 565.

[28] K.-H. Ibsand L. Rink, J. Nutr. 2003, 133, $1452 \mathrm{~S}$.

[29] D. R. Juberg in Lead and human health, ACSH, New York, 2000, pp. 11-20

[30] F. Wieberneit, A. Korste, H.B. Albada, N. MetzlerNolte, R. Stoll, Dalton Trans. 2013, 42, 9799.

[31] I. Efremenko, R. H. Fish, Organometallics 2015, 34, 4117.

[32] Š. Horvat, M. Roščić, L. Varga-Defterdarović, J. Horvat, J. Chem. Soc. Perkin Trans. 1 1998, 909.

[33] Š. Horvat, M. Roščić, C. Lemieux, T. M.-D. Nguyen, P. W. Schiller, Chem. Biol. Drug Des. 2007, 70, 30.

[34] M. Roščić, Š. Horvat, Bioorg. Med. Chem. 2006, 4, 4933.

[35] E. Vass, M. Hollósi, Š. Horvat, M. Roščić, Croat. Chem. Acta 2008, 81, 647.

[36] M. Hollósi, E. Vass, G. Szilvágyi, A. Jakas, I. Laczkó, ARKIVOC 2012, 291.

[37] R. G. Pearson, J. Am. Chem. Soc. 1963, 85, 3533.

[38] A. Perczel, M. Hollósi in Circular dichroism and the conformational analysis of biomolecules (Ed.: G. D. Fasman), Plenum, New York, 1996, pp 285-380.

[39] Z.M. Shen, A. Perczel, M. Hollósi, I. Nagypál, G. D. Fasman, Biochemistry 1994, 33, 9627.

[40] R. W Woody, A. K. Dunker in Circular dichroism and the conformational analysis of biomolecules (Ed. G. D. Fasman), Plenum, New York, 1996, pp. 109-157.

[41] Š. Horvat, A. Jakas, E. Vass, J. Samu, M. Hollósi, J. Chem. Soc. Perkin Trans. 2 1997, 1523. 